\title{
Equine pericardium: a versatile alternative reconstructive material in congenital cardiac surgery
}

\author{
Ahmed Abdelrahman Elassal ${ }^{1,2^{*}}$ D, Osman Osama AL-Radi ${ }^{1}$, Zaher Faisal Zaher ${ }^{3}$, Ahmed Mohamed Dohain ${ }^{3,4}$, \\ Gaser Abdelmohsen Abdelmohsen ${ }^{3,4}$, Ragab Sayed Mohamed ${ }^{3}$, Mazin Adel Fatani ${ }^{5}$, \\ Mohamed Esam Abdelmotaleb ${ }^{6}$, Nada Ahmed Noaman ${ }^{7}$, Mahmoud Akl Elmeligy ${ }^{8}$ and Osama Saber Eldib ${ }^{2}$
}

\begin{abstract}
Background: Pericardial patches are often used for repair of congenital cardiac defects. The aim of this study was to describe our initial experience with the use of equine pericardium and its safety and advantages and disadvantages compared to bovine pericardium.

Methods: We designed a retrospective cohort study of 111 patients who were surgically treated for congenital heart disease between 2017 and 2020. Equine pericardium was used in 58 patients and bovine pericardium was used in 53 patients. Recorded variables included demographic data, preoperative cardiac pathology, site of patch insertion, morbidity and mortality.

Results: The overall survival rate was $94.5 \%$ and no deaths were related to patch insertion. None of our patients were reoperated on for patch related complications. Postoperative transcatheter intervention was needed in 2 patients (1.8\%): one for dilatation of aortic arch stenosis after repair of hypoplastic left heart syndrome with equine pericardium and one for dilatation of pulmonary artery branches after repair of tetralogy of Fallot using bovine pericardium.
\end{abstract}

Conclusions: Equine pericardium is a safe patch material for reconstruction in congenital heart surgery. It may be preferable to bovine pericardium in cases requiring a complex shape or a pliable patch as in in arch reconstruction or for valve reconstruction.

Keywords: Equine pericardium, Congenital heart diseases, Cardiac surgery

\section{Background}

Congenital cardiac surgical procedures often require patch material for reconstruction and repair. Several materials are currently used including, most commonly, autologous pericardium, bovine pericardium, synthetic polytetrafluorethylene (PTFE). Tissue pliability,

\footnotetext{
* Correspondence: samalassal1434@gmail.com

'Department of Surgery, Cardiac Surgery Unit, King Abdulaziz University, Jeddah, Saudi Arabia

${ }^{2}$ Cardiothoracic Surgery Department, Zagazig University, Zagazig, Egypt Full list of author information is available at the end of the article
}

competence of repair, and freedom from patch related complications are important criteria that determine choice of patch material [1]. We started to use equine pericardium as a reconstructive patch material 3 years ago. The surgeon initially used equine pericardial patch material as choice of trial and evaluation then he used it interchangeably with other patch materials specially in neonatal cardiac surgery and more complex procedures. $\mathrm{He}$ opined that although equine pericardial patch was soft, pliable, thin and remodeled in proper shape, it was enough tough for blood sealing and to counter

C C The Author(s). 2021 Open Access This article is licensed under a Creative Commons Attribution 4.0 International License, which permits use, sharing, adaptation, distribution and reproduction in any medium or format, as long as you give appropriate credit to the original author(s) and the source, provide a link to the Creative Commons licence, and indicate if changes were made. The images or other third party material in this article are included in the article's Creative Commons licence, unless indicated otherwise in a credit line to the material. If material is not included in the article's Creative Commons licence and your intended use is not permitted by statutory regulation or exceeds the permitted use, you will need to obtain permission directly from the copyright holder. To view a copy of this licence, visit http://creativecommons.org/licenses/by/4.0/ The Creative Commons Public Domain Dedication waiver (http://creativecommons.org/publicdomain/zero/1.0/) applies to the data made available in this article, unless otherwise stated in a credit line to the data. 
dehiscence and aneurysms. We try her to provide observational study about equine pericardial patch material in pediatric cardiac surgery as we notice that subject is not widely published in literatures. In this study we present our experience with the use of equine pericardium in a wide range of congenital cardiac surgical procedures and how it compared to bovine pericardium.

\section{Methods}

This retrospective cohort study has been approved by Ethics Committee (EC) on 28/9/2020 and under reference number: 503-20. The consent of patients obtained. All patients who underwent any procedure with the use of equine pericardium at our institution were included and This included patient from 2017 till the study date. Patient and procedural data were collected in a prospective clinical database. Additional review of the medical records was also utilized to obtain information about possible complications and reinterventions. The equine pericardial patch (Matrix patch ${ }^{\mathrm{Tm}}$ ) manufactured by Auto Tissue, Berlin $\mathrm{GmbH}$ and certified by TÜV
Rheinland LGA Products GmbH (Fig. 1) was used. The material in approved for clinical use by the Saudi Food and Drug Authority which regulated all medical and surgical materials including implants. We included patients who underwent congenital cardiac surgery with the use of bovine pericardium ( $\mathrm{SJM}^{\mathrm{Tm}}$ pericardial patch) in the same time period as a control group. The choice of patch was made by the surgeon based on the type of repair. Generally, the surgeon preferred equine pericardium for repair requiring a complex shape patch, for example in arch reconstruction (Fig. 2), or in valve repair requiring tissue pliability. Bovine pericardium was used for simple patch shapes, for example right ventricular outflow augmentation. We excluded from the study the cases who were suitable for repair by cost effective autologous pericardial material like repair of secundum and primum atrial septal defects, sinus venosus atrial septal defects with partial abnormal pulmonary venous connections, repair of partial atrioventricular canal and any discrete pulmonary artery stenosis specially supravalvular one. We assessed the patients after surgery by

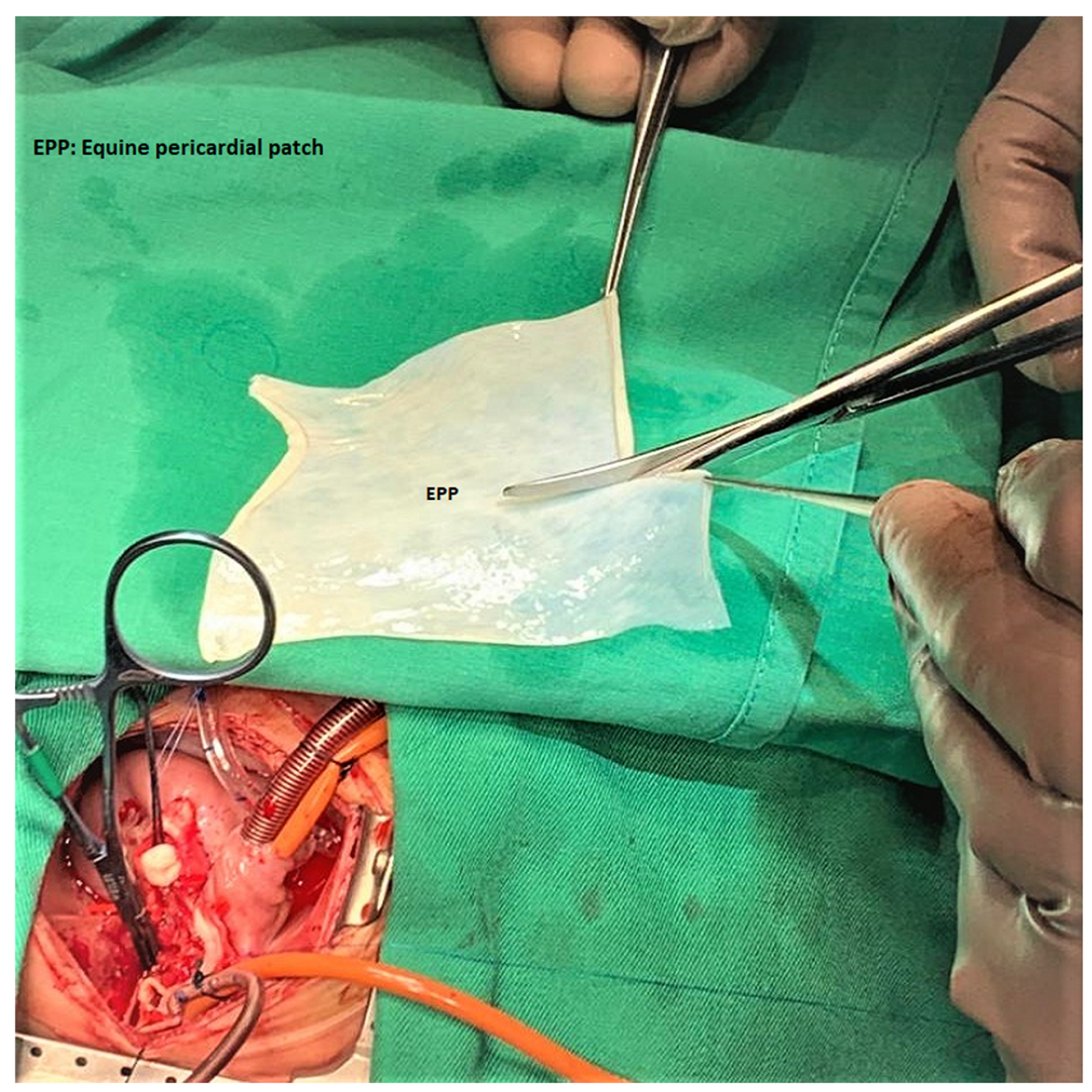

Fig. 1 Intraoperative image during repair of distal part of ascending aorta and aortic arch by using equine pericardial patch in one-month baby presented with truncus arteriosus with interrupted aortic. EPP: Equine pericardial patch 


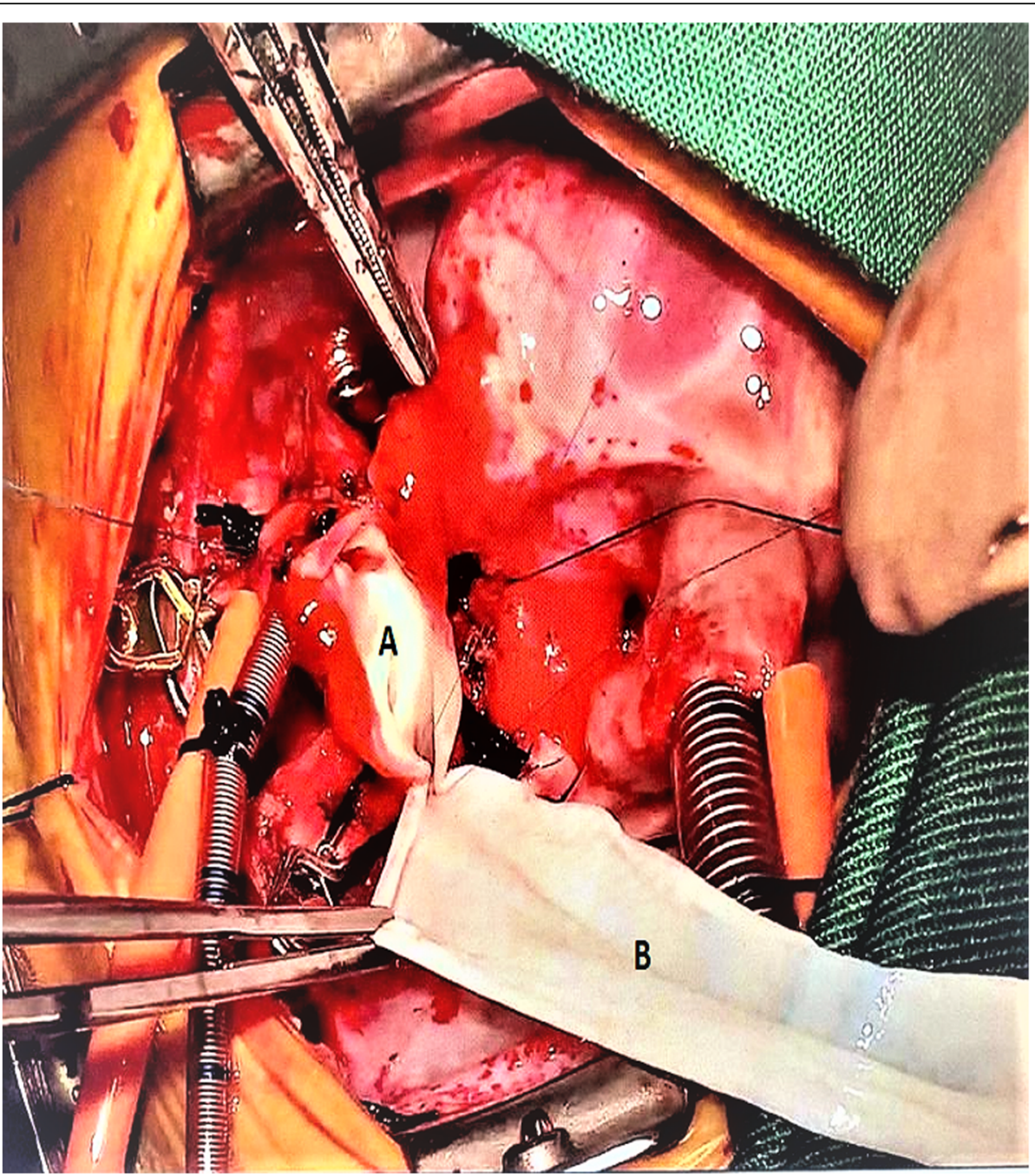

Fig. 2 Intraoperative image of the baby in Fig. 1. a Distal part of the aorta and aortic arch, b Equine pericardial patch

clinical evaluation and echocardiography as a routine for all cases and cardiac catheterization for selected cases. Accordingly, we can determine any residual lesions, other morbidities and mortality. Variables collected for comparison included: age, gender, weight, body surface area, Risk Adjustment in Congenital Cardiac Surgery (RACHS) score, preoperative cardiac pathology, site of patch insertion, morbidity, reinterventions and mortality related to patch.

\section{Statistical analysis}

Frequencies were presented as absolute number and percentage. Continuous variables were presented as median and range or mean \pm SD. Pearson's chi-squared test was used to analyze qualitative variables. Mann-Whitney rank sum test was used for continuous variables. A $p$ value $<0.05$ was taken as statistically significant.

\section{Results}

Total number of patients was 111 patients, 58 repaired with equine pericardium (EP group), and 53 repaired with bovine pericardium (BP group). Patients' characteristics are shown in Table 1 . No statistically significant difference was found between the two groups regarding age, gender, weight and RACH score. Patients in EP group had smaller BSA than those in BP group. The most common primary cardiac pathology was PA/VSD (18.9\%) and HLHS (12\%) in EP group and TOF (43.4\%) in BP group. The most frequent site for patch insertion was main pulmonary artery (26.5\%) and aortic arch (26.5\%) in EP group and RVOT (45.2\%) and VSD (30\%) in BP group (Table 2). Follow up was available for 100 patients (95.2\% of survivors). Mean follow up period was $1 \pm 0.67$ year. Outcome of patch repair is shown in Table 3. Residual stenosis and shunt were insignificant and did not necessitate intervention in both groups apart from 2 patients. The first was in BP group 
Table 1 Characteristics of patients

\begin{tabular}{|c|c|c|c|}
\hline & EP & $\mathrm{BP}$ & $P$ value \\
\hline Number of patients & 58 & 53 & \\
\hline Age (median, range). & 343.5 days (2-1439) & $531(14-9223)$ & 0.06 \\
\hline Gender M/ F & $32 / 26$ & $34 / 19$ & 0.33 \\
\hline Weight & $10.96 \pm 11.33$ & $14.15 \pm 14.46$ & 0.08 \\
\hline BSA & $0.46 \pm 0.33$ & $0.58 \pm 0.33$ & 0.03 \\
\hline RACHS & $5.5 \pm 2.1$ & $5 \pm 1$ & 0.11 \\
\hline \multicolumn{4}{|l|}{ Primary diagnosis } \\
\hline \multicolumn{4}{|l|}{ Left sided lesions } \\
\hline HLHS & 7 & 0 & \\
\hline Coarctation/ hypoplastic aortic arch & 5 & 0 & \\
\hline Interrupted aortic arch & 2 & 3 & \\
\hline Supravalvular aortic stenosis & 3 & 0 & \\
\hline LVOT obstruction & 0 & 1 & \\
\hline Mitral stenosis & 1 & 1 & \\
\hline Mitral regurgitation & 2 & 0 & \\
\hline Congenital aortic stenosis & 1 & 1 & \\
\hline Aortic regurgitation & 3 & 0 & \\
\hline \multicolumn{4}{|l|}{ Right sided lesions } \\
\hline PANSD & 11 & 4 & \\
\hline DORV & 3 & 3 & \\
\hline RVOT obstruction & 1 & 0 & \\
\hline Pulmonary artery stenosis & 2 & 1 & \\
\hline Pulmonary valve stenosis & 0 & 1 & \\
\hline \multicolumn{4}{|l|}{ Other } \\
\hline Truncus arteriosus & 1 & 2 & \\
\hline TGA & 5 & 3 & \\
\hline TOF & 7 & 23 & \\
\hline VSD & 2 & 5 & \\
\hline AVSD & 0 & 4 & \\
\hline Aortopulmonary window & 0 & 1 & \\
\hline Endocarditis & 1 & 0 & \\
\hline Pulmonary vein stenosis & 1 & 0 & \\
\hline
\end{tabular}

where transcatheter dilatation of right and left pulmonary arteries was done after repair of TOF during the same admission. The second patient was operated for HLHS using EP. Postoperative echocardiography showed high gradient along the aortic arch and was dilated by balloon dilation with good response. No other patch related complications (e.g. infection, dehiscence, or bleeding from suture lines) were found in either group. No mortality was related to patch insertion.

\section{Limitation of the study}

This is study is retrospective single center experience study of small volume and follow up is quite short.
Prospective study of large volume with intermediate and long term follow up will provide a more evidence-based conclusion.

\section{Discussion}

Surgical procedures for correction of congenital cardiac diseases are often accomplished with use of patch material. Autologous pericardium is not usually sufficient especially in reoperations or staged procedures. A diverse range of patches including synthetic or xenogeneic are available as tissue substitutes. Ideal patch should be readily available, easy to handle, has growth potential, can recellularize, remodel, resist infection and coapt well 
Table 2 Sites of patch insertion

\begin{tabular}{|c|c|c|}
\hline & No. of EP patches & No. of BP patches \\
\hline \multicolumn{3}{|l|}{ RVOT } \\
\hline Infundibular & 10 & 15 \\
\hline Transannular & 0 & 9 \\
\hline \multicolumn{3}{|l|}{ Pulmonary arteries } \\
\hline Main & 16 & 10 \\
\hline Right & 7 & 0 \\
\hline left & 8 & 1 \\
\hline \multicolumn{3}{|l|}{ Aorta } \\
\hline Root & 5 & 0 \\
\hline Ascending & 9 & 2 \\
\hline Arch & 16 & 1 \\
\hline Descending & 1 & 2 \\
\hline \multicolumn{3}{|l|}{ Defects } \\
\hline VSD & 0 & 17 \\
\hline \multicolumn{3}{|l|}{ Valves } \\
\hline Aortic & 4 & 1 \\
\hline Mitral & 3 & 1 \\
\hline Tricuspid & 1 & 0 \\
\hline Pulmonary & 1 & 1 \\
\hline \multicolumn{3}{|l|}{ Others } \\
\hline Innominate vein & 1 & 0 \\
\hline Pulmonary veins & 1 & 0 \\
\hline LVOT & 0 & 1 \\
\hline Total no. of patches & 83 & 61 \\
\hline
\end{tabular}

to suture lines for proper hemostasis and lower thrombogenicity [2, 3]. Unfortunately, none of the available patches meet all of these criteria. Synthetic patches e.g. Dacron and Gore-Tex cannot remodel, regenerate, nor grow. They are liable to infection stiffening and calcification over time after implantation [4]. Bioprosthetic patches show better surgical handling and more resistance to infection than synthetic patches. Processing of xenopericardium (decellularization) is important to remove cellular antigens and procalcific materials while maintaining integrity of extracellular matrix. In addition, cross linking (by agents e.g. glutaraldehyde) increases stability and strength of tissue and keeps it nonantigenic [5, 6]. However, late calcification is not uncommon and may be related to the type of processing and decellularization as well as the anticalcific treatment.

Tissue engineering is adopted to avoid some of these drawbacks. The bovine pericardial patch (CardioCel) is treated to remove antigens and calcium binding phospholipid sites, thus limiting calcification and reducing reoperation [7]. Dye-mediated photo oxidation is an alternative to glutaraldehyde for cross linking of collagen fibers in bovine pericardium (Photofix) [8].

Limitations related to availability and costs of these types are considered in our choice. We are still using autologous and bovine pericardia for repair. Equine pericardium has been introduced at our center for the last 3 years. EP is a decellularized patch not fixed with glutaraldehyde. Subjectively we found it softer, more pliable, and easier for handling especially in areas requiring a complex patch shape. It shows excellent adaptation to tissues notably in reconstruction of the aorta in neonates with HLHS or other complex arch pathology.

An interesting animal study by Dohmen et al. showed favorable characteristics of EP. Decellularized equine pericardia were implanted into the descending aorta of juvenile sheep. Explanation was done after 4 months. There was no evidence of thrombosis, infection, calcification, or degeneration. Extracellular matrix was preserved. A monolayer of endothelial cells was noticed on the inner side of the patch and neovascularization was

Table 3 Outcomes of patch repair

\begin{tabular}{|c|c|c|c|c|}
\hline \multirow{2}{*}{\multicolumn{2}{|c|}{$\overline{\text { Recurrent stenosis }}$}} & \multirow[t]{2}{*}{ Number of cases with EP } & \multirow[t]{2}{*}{ Number of cases with BP } & \multirow[t]{2}{*}{$P$ value } \\
\hline & & & & \\
\hline \multicolumn{2}{|c|}{ Main pulmonary artery } & 3 & 2 & \\
\hline \multicolumn{2}{|c|}{ Pulmonary artery branches } & 0 & 1 & \\
\hline \multicolumn{2}{|l|}{ Aorta } & 2 & 0 & 0.26 \\
\hline \multicolumn{2}{|c|}{ Pulmonary veins } & 1 & 0 & \\
\hline \multicolumn{2}{|c|}{ Residual VSD } & 0 & 1 & \\
\hline \multicolumn{2}{|c|}{ Need for catheter intervention } & 1 & 1 & \\
\hline \multirow[t]{5}{*}{ Mortality } & Total No. & $5(8.6 \%)$ & $1(1.88 \%)$ & 0.11 \\
\hline & Causes of death & Intracranial hemorrhage (1) & RV failure (1) & \\
\hline & & Pulmonary hemorrhage (1) & & \\
\hline & & Respiratory failure (2) & & \\
\hline & & Low cardiac output (1) & & \\
\hline
\end{tabular}


found in the outer side. This study showed remodeling and regeneration of equine pericardium [9].

EP is successfully used in varying surgical sites. EP is also used as dural substitute. It is transparent, impermeable to CSF, does not adhere to cortex and facilitates regeneration of dura. It has the advantages of greater physical resistance and less liability to infection than bovine pericardium [10]. EP was also used in myringoplasty (to close tympanic membrane perforation). Long-term closure rate was better in EP group compared to BP (bovine pericardium). EP is thinner, easier to handle and remodel in proper shape than BP [11]. EP is used in treatment of chronic wounds and ulcers of diabetic foot. It provides temporary biological cover scaffold that promote healing [12]. Few data are found in literature regarding use of equine pericardium in cardiovascular surgery. EP was approved for pediatric cardiac reconstructive surgery and was successfully used as a substitute to arterial homograft to replace infected aortic aneurysm [13, 14]. Equine pericardial patch is used to close the pericardial sac to decrease risk of repeat sternotomy. Lesser adhesions were found in equine pericardial patched group when compared with pericardium left open group [15]. On the contrary others reported intense epicardial reactions, degeneration, and calcification. This discouraged most surgeons from using xenopericardium for closure of pericardial sac [16]. We do not routinely close the pericardium in pediatric patients. We think that glutaraldehyde added to fix pericardial patch might account for these undesirable changes. Accordingly, glutaraldehyde-free Matrix patch ay be a better alternative. An experimental study was conducted by Rassoli et al. compared equine, bovine, and porcine pericardia mechanically and histologically. Equine pericardium showed less stiffness under biaxial tension and hence it is more appropriate for manufacturing bioprosthetic valves as recommended by authors [17]. EP was used to construct a stentless bioprosthetic valve with good hemodynamic results comparable to Toronto SPV valve as shown in an animal study by Muller and Segsser [18]. We used EP for augmentation of valve repair in 9 cases with good results in terms of coaptation and competence. We prefer to do bicuspidization of pulmonary valves with EP. Early follow up results of our series showed favorable outcomes of EP comparable to BP with respect to survival and freedom from reoperations. A few clinical trials compared the use of EP and BP in surgery for congenital cardiac diseases. Vitanova et al. reported higher rate of recoarctation after Norwood stage 1 for HLHS when equine pericardium was used for reconstruction of aortic arch in comparison to homograft, autologous pericardium, and bovine pericardium. They concluded that equine pericardium was the only risk factor for recoarctation and cannot be recommended for repair of HLHS [19]. We operated 7 patients in our series with HLHS using EP. Transcatheter dilatation was needed for one patient and responded well to dilatation. The remaining patients had excellent arch reconstruction using EP and many have undergone second and final stage surgery without evidence of significant calcification or stenosis.

The cost of different materials varies in different countries. However, in Saudi Arabia the coast of the EP is comparable to BP (EP cost is 900 dollars and BP cost is 825 dollars). We agree with Veličković et al. [20] that the rate of revision or reoperation related to patch failure should be considered when economic aspect is evaluated.

This study is a retrospective single center study including a relatively small number of patients with different congenital cardiac diseases. Prospective studies with larger sample size and longer follow up period are needed to evaluate long term outcome.

\section{Conclusions}

We conclude that equine pericardium is safe and efficient tissue substitute for repair of congenital cardiac defect with comparable results to bovine pericardium and is preferable in our experience for cases requiring complex arch reconstruction or valve repair.

\section{Abbreviations}

PTFE: Polytetrafluorethylene; RACHS: Risk Adjustment in Congenital Cardiac Surgery; EP: Equine pericardium; BP: Bovine pericardium; BSA: Body surface area; PANSD: Pulmonary atresia with ventricular septal defect;

HLHS: Hypoplastic left heart syndrome; TOF: Tetralogy of Fallot; RVOT: Right ventricular outflow tract

\section{Acknowledgements}

This project was funded by the Deanship of Scientific Research (DSR), King Abdulaziz University, under grant No. (DF- 825 - 140 - 1441). The authors, therefore, gratefully acknowledge the DSR technical and financial support.

\section{Authors' contributions}

The idea, methodology and data analysis were done by Ahmed Elassal, Osman AL- Radi and Osama Saber. Data collection by Ragab Mohamed and Mohamed Abdelmotaleb. Editing and language revision were performed by Ahmed Dohain, Zaher Zaher, Nada Noaman and Mazin Fatani. Images were formatted by Mahmoud Elmeligy. The project was revised by Osman ALRadi. The authors read and approved the final manuscript.

\section{Funding}

This project was funded by the Deanship of Scientific Research (DSR), King Abdulaziz University, under grant No. (DF- 825 - 140 - 1441).

\section{Availability of data and materials}

The datasets used and/or analysed during the current study are available from the corresponding author on reasonable request.

\section{Declarations}

Ethics approval and consent to participate

This study has been approved by Ethics Committee (EC) on 28/9/2020 and under reference number:503-20. The consent of patients obtained.

Consent for publication

Not applicable. 


\section{Competing interests}

All authors declare that they have no competing interests.

\section{Author details}

'Department of Surgery, Cardiac Surgery Unit, King Abdulaziz University, Jeddah, Saudi Arabia. ${ }^{2}$ Cardiothoracic Surgery Department, Zagazig University, Zagazig, Egypt. ${ }^{3}$ Department of Pediatric Cardiology, King Abdulaziz University, Jeddah, Saudi Arabia. ${ }^{4}$ Pediatric Cardiology Division, Department of Pediatrics, Cairo University, Cairo, Egypt. ${ }^{5}$ Department of Surgery, Umm Al-Qura University, Makkah, Saudi Arabia. ${ }^{6}$ Pediatric Cardiac Intensive Care Unit, King Abdulaziz University, Jeddah, Saudi Arabia. ${ }^{7}$ Department of Anesthesia and Critical Care, King Abdulaziz University, Jeddah, Saudi Arabia. ${ }^{8}$ Department of Surgery, Cardiac Surgery Unit, Cardiopulmonary Perfusion Unit, King Abdulaziz University, Jeddah, Saudi Arabia.

Received: 9 February 2021 Accepted: 9 April 2021

Published online: 23 April 2021

\section{References}

1. Pok S, Jacot JG. Biomaterials advances in patches for congenital heart defect repair. J Cardiovasc Transl Res. 2011:4(5):646-54.

2. Mather C, Treuting P. Onchocerca armillata contamination of a bovine pericardial xenograft in a human patient with repaired tetralogy of Fallot. Cardiovasc Pathol. 2012;12(3):e35-8.

3. lop L, Palmosi T, Sasso ED, et al. Bioengineered tissue solutions for repair, correction, and reconstruction in cardiovascular surgery. J Thorac Dis. 2018; 10(Suppl 20):S2390-411.

4. Vaideeswar P, Mishra P, Nimbalkar M. Infective endocarditis of the Dacron patch-a report of 13 cases at autopsy. Cardiovasc Pathol. 2011;20:e169-75.

5. Nataraj C, Ritter G, Dumass S, et al. Extracellular wound matrices: novel stabilization and sterilization method for collagen-based biologic wound dressing. Wounds. 2007;19:148.

6. Rémi E, Khelil N, Di Centa I, et al. Pericardial Processing: Challenges, Outcomes and Future Prospects. In: Pignatello R, editor. Biomaterials Science and Engineering; 2011. p. 437-56.

7. Neethling WM, Strange G, Firth L, et al. Evaluation of a tissue-engineered bovine pericardial patch in paediatric patients with congenital cardiac anomalies: initial experience with the ADAPT-treated CardioCel(R) patch. Interact Cardiovasc Thorac Surg. 2013;17(4):698-702.

8. Baird C W, Myers PO, Piekarski B, et al. Photo-oxidized bovine pericardium in congenital cardiac surgery: single-Centre experience. Interact Cardiovasc Thorac Surg. 2017;24:240-4.

9. Dohmen PM, Costa F, Lopes SV, et al. Successful implantation of a decellularized equine pericardial patch into the systemic circulation. Med Sci Monit Basic Res. 2014;20:1-8.

10. Montinaro A, Gianfreda CD, Proto P. Equine pericardium for Dural grafts: clinical results in 200 patients. J Neurosurg Sci. 2007:51(1):17-9.

11. Albera $R$, Dagna $F$, Lacilla $M$, et al. Equine versus bovine pericardium in transmeatal underlay myringoplasty. Ann Otol Rhinol Laryngol. 2009;118(4): 287-91

12. Alexander $\mathrm{JH}$, Yeager DA, Stern DS, et al. Equine pericardium as a biological covering for the treatment of diabetic foot wounds. A prospective study. J Am Podiatr Med Assoc. 2012;102(5):352-8.

13. Kubota $\mathrm{H}$, Endo $\mathrm{H}$, Noma $\mathrm{M}$, Tsuchiya $\mathrm{H}$, et al. Equine pericardial roll graft replacement of infected pseudoaneurysm of the ascending aorta. J Cardiothorac Surg. 2012;7:54

14. Kubota H, Endo H, Noma M, et al. Xenopericardial roll graft replacement for infectious pseudoaneurysms and graft infections of the aorta. J Cardiothorac Surg. 2015;10:133.

15. Segesser $L$, Jornod N, Faidutti B. Repeat sternotomy after reconstruction of the pericardial sac with glutaraldehyde-preserved equine pericardium. J Thorac Cardiovasc Surg. 1987;93:616-9.

16. Boyd WD, Tyberg JV, Cox JL. A review of the current status of pericardial closure following cardiac surgery. Expert Rev CardiovascTher. 2012;10(9): 1109-18.

17. Rassoli A, Fatouraee N, Guidoin R, et al. Comparison of tensile properties of xenopericardium from three animal species and finite element analysis for bioprosthetic heart valve tissue. Artif Organs. 2020;44(3):278-87.

18. Mueller X, Segesser LK. A new equine pericardial stentless valve. J Thorac Cardiovasc Surg. 2003;125:1405-11.
19. Vitanova K, Cleuziou K, Ohain JP, et al. Recoarctation after Norwood I procedure for hypoplastic left heart syndrome: impact of patch material. Ann Thorac Surg. 2017;103:617-21.

20. Veličković VM, Borisenko O, Svensson M, et al. Congenital heart defect repair with ADAPT tissue engineered pericardium scaffold: an early-stage health economic model. PLoS One. 2018;13(9):e0204643.

\section{Publisher's Note}

Springer Nature remains neutral with regard to jurisdictional claims in published maps and institutional affiliations.
Ready to submit your research? Choose BMC and benefit from:

- fast, convenient online submission

- thorough peer review by experienced researchers in your field

- rapid publication on acceptance

- support for research data, including large and complex data types

- gold Open Access which fosters wider collaboration and increased citations

- maximum visibility for your research: over $100 \mathrm{M}$ website views per year

At BMC, research is always in progress.

Learn more biomedcentral.com/submissions 